\title{
Association between trans-fatty acids in erythrocytes and pro-atherogenic lipid profiles among Canadian Inuit of Nunavik: possible influences of sex and age
}

\author{
Emilie Counil $^{1 *}$, Pierre Julien ${ }^{2}$, Benoit Lamarche ${ }^{3}$, Marie-Ludivine Château-Degat ${ }^{1,4}$, Annie Ferland ${ }^{1}$ \\ and Eric Dewailly ${ }^{1}$ \\ ${ }^{1}$ Public Health Research Unit, CHUL Research Centre, Québec, QC, Canada \\ ${ }^{2}$ Lipid Research Centre, CHUL Research Centre, Québec, QC, Canada \\ ${ }^{3}$ Nutraceuticals and Functional Foods Institute, Québec, QC, Canada \\ ${ }^{4}$ School of Dietetics and Human Nutrition, McGill, Ste-Anne de Bellevue, QC, Canada
}

(Received 17 September 2008 - Revised 6 January 2009 - Accepted 23 January 2009 - First published online 18 May 2009)

\begin{abstract}
Dietary exposure to trans-fatty acids (TFA) is likely to be high among Canadian Inuit; yet no data are available on the physiological effects of TFA in this population. The purpose of the present study was to assess the association between TFA and plasma lipid profiles in Inuit men and women living in Nunavik (Québec, Canada). In a cross-sectional, population-based survey, a total of 795 Nunavik Inuit eligible participants gave a blood sample. Exposure to TFA was assessed by their relative proportion in erythrocyte membrane. We performed multiple regression analysis using plasma lipids or their linear combinations as the dependent variables and TFA as the main predictor, adjusting for potential confounders. The associations varied markedly between the sexes and according to age. In men ( $n$ 357, aged 36.3 (SD 14.3) years, TFA 1.24 (SD 0.54) \%), TFA tended to be negatively associated with HDL-cholesterol (HDL-C), apoA1 and LDL particle size, and positively associated with non-HDL-C, LDL-cholesterol (LDL-C), apoB100, the apoB100:apoA1 ratio and the ratios of total cholesterol (TC), LDL-C and TAG to HDL-C. No such trends were observed in women ( $n$ 438, aged 37.0 (SD 14.1) years, TFA 1.16 (SD 0.54) \%), except for HDL-C and apoA1 in women aged 50 years and more. These results suggest that TFA could raise the risk of CHD in Inuit men at least through their physiological effects on plasma lipids. The differential associations reported in pre- and postmenopausal women need to be reproduced in other populations and in experimental studies addressing the influence of sex hormones in response to dietary fats.
\end{abstract}

Trans-fatty acids: Hydrogenated fat: Lipoproteins: Cholesterol: Diet

The association between trans-fatty acid (TFA) intake and the risk of CHD has been mainly evaluated in Caucasian populations ${ }^{(1-4)}$. Yet, Arctic populations from Northern America may be particularly exposed to TFA due to the rapid sociocultural transition they experience and specific food constraints over the Northern food supply. Several studies actually report that the reliance on a traditional, marine diet decreased over the last decades for the benefit of a more Western $\operatorname{diet}^{(5,6)}$, especially in youth ${ }^{(7,8)}$, a process referred to as the Inuit dietary transition. Moreover, easy-to-eat products such as snack foods are usually appreciated among Inuit since they allow to satisfy one's hunger according to one's own biological rhythm ${ }^{(9)}$. Those products are likely to contain large amounts of industrially produced TFA which have practical qualities (palatability, low cost, storability at room temperature and long shelf life) that are all valuable to the food supply of remote communities.

Previous research conducted in Nunavik (Northern Québec) Inuit $^{(10)}$ actually showed that the proportion of trans-monoenes in erythrocyte phospholipids (PL), a validated biomarker of TFA long-term intake ${ }^{(11)}$, was comparable with what has been described in the Nurses' Health Study ${ }^{(12)}$ and slightly lower than those found in the Genetics of Lipid-Lowering Drugs and Diet Network (GOLDN) Study ${ }^{(13)}$. On the other hand, the proportion of $n-3$ fatty acids was also very high among Nunavik Inuit, especially among elders, which could confer some cardiometabolic protection ${ }^{(14,15)}$.

Furthermore, controlled dietary trials strongly suggest that the association between TFA and the risk of CHD is in part explained by their effects on blood lipoprotein profiles ${ }^{(16,17)}$, but few observational studies have been conducted so far on the association between TFA and such early outcomes ${ }^{(12,13)}$.

The aim of the present study was thus to bring further insight into the association between TFA measured in erythrocytes and plasma lipid profiles through an observational survey conducted among Inuit men and women living in Nunavik enrolled in the baseline of the Inuit Health in Transition Cohort Study, that is, a young population, ethnically homogeneous, which experiences a marked dietary

Abbreviations: HDL-C, HDL-cholesterol; HOMA-IR, homeostatic model assessment of insulin resistance; LDL-C, LDL-cholesterol; PL, phospholipid; TC, total cholesterol; TFA, trans-fatty acid.

* Corresponding author: Dr Emilie Counil, fax +1 418654 2726, email Emilie.Counil@crchul.ulaval.ca 
transition implying the coexistence of potential protective and risk factors for CHD.

\section{Subjects and methods}

\section{Study design and selection of subjects}

The territory of Nunavik lies north of the 55th parallel in Québec (Canada). According to the 2001 Canadian census, there are 9632 inhabitants (10784 in 2006), $91 \%$ of whom identify themselves as Inuit. The entire population spreads in fourteen coastal villages. The Nunavik Health Survey 2004 entitled 'Qanuippitaa? How are we?' used a complex twostage stratified random sampling plan of private Inuit households to select a representative sample of the population aged 15 years and over living in the fourteen Inuit communities of Nunavik ${ }^{(18)}$. The assumption was that recruiting a member of the household rather than a specific individual would increase coverage of the target population. The community of residence was the only stratification variable used. It was important to choose households from all fourteen communities since the distances separating the villages could be associated with significant differences in lifestyle. To obtain a good representation of each community, a proportional allocation of sample units according to the size of each village was chosen. The first stage was thus to select a stratified random sample of private Inuit households with proportional allocation. Among the 677 households visited by the interviewers, 521 agreed to participate in the survey. The household response rate was thus $77.8 \%$. In the second stage, all eligible individuals in participating households were asked to take part. A total of 1056 individuals signed a consent form and completed at least one test or one questionnaire. Among them, 929 aged 18 years and over accepted to participate in a longitudinal follow-up component of the study: the Inuit Health in Transition Cohort Study. This component involved permission to follow participants over time as well as permission to review individual medical charts. Participants were interviewed during a 3-4h visit, went through paraclinical examinations and had a blood sample drawn. Response rate varied from $40.0 \%$ (24 h dietary recall) to $54.1 \%$ (venous blood puncture).

We excluded non-Inuit individuals ( $n$ 22), pregnant women ( $n$ 26), individuals with incomplete data ( $n$ 55) and individuals with elevated TAG $(\geq 1.7 \mathrm{mmol} / \mathrm{l})$ who reported fasting for less than $8 \mathrm{~h}$ before venepuncture ( $n$ 31). The study sample thus included 795 Inuit participants.

\section{Specimen collection and analysis}

Participants were advised to fast for at least $8 \mathrm{~h}$ before blood sample collection, technicians used a standardised phlebotomy protocol, and plasma was stored at $-80^{\circ} \mathrm{C}$. We measured the fatty acid composition of PL of erythrocyte membranes after total lipid extraction with a chloroform-methanol mixture, PL separation by TLC $^{(19)}$ and methylation of fatty acids ${ }^{(20)}$, followed by capillary GLC using an HP-88 column (for TFA, $100 \mathrm{~m} \times 0.25 \mathrm{~mm}$ internal diameter $\times 0.20 \mu \mathrm{m}$ thickness; Agilent Technologies, Oakville, Ontario, Canada) in a Hewlett-Packard 5890 GC chromatograph (Hewlett Packard, Toronto, Ontario, Canada) coupled with a flame ionisation detector; the carrier gas used was He (split ratio 1:80). Fatty acids were identified according to their retention time, using standard mixtures as a basis for comparison (the FAME 37 mix (Supelco Inc., Bellefonte, PA, USA) and the GLC-411 fatty acid mix (NuChek Prep Inc., Elysian, MN, USA)), as well as the following methylated fatty acids: 22 : 5n-6 (Larodan AB, Malmö, Sweden) and $22: 5 n-3$ (Supelco Inc.). A mixture of TFA containing $18: 2 n$ 6 cis/trans (Supelco Inc.), a mixture of cis/trans $18: 3 n-3$ (Supelco Inc.), the fatty acids $14: 1$ trans -9 and 16:1 trans -9 (NuCheck) and finally isoforms of 18:1 (cis-6, trans-6, cis-11, trans-11, NuChek Prep Inc.; and cis-12, cis-13, Supelco Inc.) was also used as a standard mixture. Results were expressed as percentage of total fatty acids. Ten trans-isomers were detected (see footnote of Table 3). Plasma lipid concentrations were analysed according to methods from the Lipid Research Clinic (US Department of Health): total cholesterol (TC) and TAG concentrations were determined using an Auto-Analyser II (Technicon Instruments Corp., Tarrytown, NY, USA); the HDL-cholesterol (HDL-C) fraction was obtained after precipitation of LDL-cholesterol (LDL-C) in the infranatant fraction with heparin and manganese chloride $^{(21)}$. LDL-C was then calculated using the Friedewald equation $^{(22)}$ and non-HDL-C was calculated as the difference between TC and HDL-C. Concentrations of apoA1 and apoB100 were measured by immunonephelometry ${ }^{(23)}$. LDL-C particle size (and LDL-peak) was characterised using $2 \%$ to $16 \%$ polyacrylamide gradient gel electrophoresis ${ }^{(24)}$. For each participant, the integrated LDL particle size (LDL integrated particle diameter) corresponded to the weighted mean computed by integrating the relative contribution of each LDL subclasses on the gel. The LDL peak particle diameter represented the size of the most abundant LDL subfraction within each individual. Fasting plasma glucose (FPG) and insulin (FPI) were measured using the Elecsys-2010 system from Roche (Basel, Switzerland). The homeostatic model assessment of insulin resistance (HOMA-IR) was calculated as follows ${ }^{(25)}$ :

$$
\begin{aligned}
& \text { HOMA }- \text { IR }=\text { FPI }(\mu \mathrm{U} / \mathrm{ml}) \times \mathrm{FPG}(\mathrm{mmol} / 1) / 22 \cdot 5 \\
& \text { HOMA - IR is dimensionless. }
\end{aligned}
$$

\section{Anthropometric and physiological measurements}

Resting blood pressure was taken in a sitting position after a 5 min rest using mercury sphygmomanometers according to standard procedures ${ }^{(26)}$. Subjects were instructed to avoid eating or smoking $30 \mathrm{~min}$ before the measurements. Body weight and composition were measured with a bioelectrical impedance analyser (Tanita TBF-300; Tanita Corp., Arlington Heights, IL, USA). Height was measured in a standing position, with the subjects' back against the wall and looking straight ahead, arms hanging on both sides. Waist circumference was measured in centimetres using a graduated tape at the narrowest circumference of the trunk, at the end of a normal expiration. When the narrowest circumference was not sufficiently defined, the measurement was taken at the level of the last rib $^{(27)}$.

\section{Questionnaire-based information}

Participants gave sociodemographic and lifestyle information (notably alcohol consumption and smoking habits) through interview-based questionnaires. We reviewed the participants' 
medical charts and recorded health antecedents and the use of medication. Participants also completed one $24 \mathrm{~h}$ recall and a sixty-nine-item FFQ. While using this dietary information in the present study, we excluded participants with energy intakes below 500 and above $3500 \mathrm{kcal} / \mathrm{d}$ (below 2092 and above $14644 \mathrm{~kJ} / \mathrm{d}$ ) for women and below 800 and above $4200 \mathrm{kcal} / \mathrm{d}$ (below 3347 and above $17572 \mathrm{~kJ} / \mathrm{d}$ ) for men.

\section{Ethics}

The survey was approved by the Comité d'éthique à la recherche de l'Université Laval and the Comité d'éthique de santé publique du Québec. Participants provided written consent.

\section{Statistical analyses}

In order to account for the complex sampling design and partial non-response rates, we applied a bootstrap approach and performed all analyses on a weighed dataset with the SASCallable SUDAAN 9.0 (Research Triangle Institute, Research Triangle Park, NC, USA) computer package. The bootstrap approach to design-based variance estimation is actually used increasingly in the survey sampling community. The bootstrap belongs to a family of variance estimation techniques known as replicate-based variance estimation. Such methods accommodate a variety of study designs by using the existing sample to build 'synthetic' samples - typically 500 - called replicates, to compute standard errors for estimates of means, regression coefficients, and other test statistics. This increases accuracy of variance estimates, hence decreasing the risk of reporting-biased significance tests. The Institut de la Statistique du Québec was given the mandate of calculating sets of sampling weights for each of our survey instruments ${ }^{(18)}$

Contrary to most commonly used statistical packages which do not account for complex sample designs when computing variance estimates and test statistics, SUDAAN permits adjustment for single- as well as multi-stage stratification through robust variance estimation methods such as balanced repeated replication (BRR) using bootstrap weights. In the present study, the standard error of each parameter of interest was computed as follows: SUDAAN estimated the parameter for each of the 500 replicated samples, and then used the variability among the 500 estimates to derive accurate variance estimates.

We performed multiple linear regression analysis using plasma lipid concentrations as the dependent variables and the percentage of TFA in erythrocyte membrane PL as the main predictor. Since plasma lipid response to dietary fat differs by age and sex, especially depending on menopausal status $^{(28)}$, we stratified analyses on sex. We considered the following factors as potential confounders: age, waist girth, the proportion of $n-3$ and $n-6$ fatty acids in erythrocyte PL, smoking status (current smoker, non-smoker), consumption of any type of alcohol (non-drinker, $\leq 10 \mathrm{~g} / \mathrm{d}, 10-30 \mathrm{~g} / \mathrm{d}, \geq 30 \mathrm{~g} / \mathrm{d}$ ) and region of residence (Ungava $v$. Hudson Bay). We also included covariates that could influence plasma lipid concentrations: fasting status (at least $8 \mathrm{~h}$ before venepuncture), elevated TAG ( $\geq 1.7 \mathrm{mmol} / \mathrm{l})$ and lipid-lowering medication taken at the time of the survey. All continuous variables were log-transformed to improve normality except for age. We checked for influential data (both outliers and high leverage observations) and multicollinearity in order not to include explanatory variables that would be near-perfect linear combinations of one another.

Finally, complementary analysis included the use of additional information extracted from the FFQ which allowed the assessment of SFA intake and its inclusion as a covariate in alternative models. The association between blood TFA and potential food contributors was assessed through simple Pearson correlations based on the FFQ-reported quantity of food consumed over the last year (in order to take seasonality into account) for country foods and over the last month for store-bought foods.

\section{Results \\ Cardiometabolic profile}

The baseline characteristics of the 795 participants retained in the analysis are given in Table 1. Our group was characterised by a young mean age (36.6 (SD 14.2) years), overweight (BMI 27.2 (SD 5.6$) \mathrm{kg} / \mathrm{m}^{2}$ ), a very low prevalence of diabetes mellitus $(4.1 \%)$, a prevalence of hypertension comparable with the Canadian population $(19.5 \%)$, a very high prevalence of smoking $(78.0 \%)$, as well as low annual income $(53.9 \%$ lower than $\$ 20000)$ and lower level of education $(77.3 \%$ did not complete secondary degree). Plasma lipid profiles (Table 2) were within a normal range. We observed significant sex differences: although women experienced central obesity (mean waist circumference $91.4(\mathrm{SD} \mathrm{14.3}) \mathrm{cm}$ ), they had higher HDL-C (1.82 v. $1.49 \mathrm{mmol} / \mathrm{l} ; P<0.0001)$ and apoA1 $(1.78$ v. $1.62 \mathrm{~g} / \mathrm{l} ; P<0.0001)$ concentrations, lower LDL-C $(2.72$ v. $2.83 \mathrm{mmol} / \mathrm{l} ; \quad P<0.05)$ and non-HDL-C $(3.22 v$. $3.36 \mathrm{mmol} / \mathrm{l} ; P<0.05)$ concentrations and subsequently lower TC:HDL-C (2.9 v. 3.5; $P<0.0001)$, LDL-C:HDL-C $(1.6 v$. $2 \cdot 1 ; P<0.0001)$, TAG:HDL-C (0.68 v. 0.87; $P<0.0001)$ and apoB100:apoA1 $(0.54$ v. $0.60 ; P<0.0001)$ ratios than did men. Moreover, LDL particles were on average of greater size in women $(256 \cdot 2$ v. $255 \cdot 3 \AA$ for LDL integrated particle diameter $(P<0 \cdot 0001) ; 256.1$ v. $255.4 \AA$ for LDL peak particle diameter $(P<0 \cdot 0001))$.

\section{Erythrocyte fatty acid profile}

The mean relative proportions of fatty acids in erythrocyte membrane PL are reported in Table 3. Only TFA and PUFA are reported for the present purpose. TFA reached $1.20 \%$, ranging from $0.79 \%$ in the oldest (individuals aged 65 years and more) to $1.35 \%$ in the youngest age group (18-24 years). Men had a slightly higher mean proportion of TFA than did women $(1.24$ v. $1.16 \% ; P<0 \cdot 01)$. Among the ten trans-isomers analysed, only trans-monoenes contributed significantly to PL composition as shown in Fig. 1. Using the HP-88 column designed to distinguish isomers of TFA, Fig. 1 also indicates that 18:2 fatty acids, when present in erythrocytes, do not co-migrate with other fatty acids. Elaidic acid contributed the most to the total of TFA $(0.63 \%)$. The relative proportion of $n-3$ fatty acids was high (on average $9.5 \%$ ), and women had higher contents than 
Table 1. Baseline characteristics of study participants

(Numbers of participants and percentages or mean values and standard deviations)

\begin{tabular}{|c|c|c|c|c|c|c|}
\hline & \multicolumn{2}{|c|}{ All $(n 795)$} & \multicolumn{2}{|c|}{ Men $(n 357)$} & \multicolumn{2}{|c|}{$\begin{array}{l}\text { Women } \\
\text { (n 438) }\end{array}$} \\
\hline & $n$ & $\%$ & $n$ & $\%$ & $n$ & $\%$ \\
\hline \multicolumn{7}{|l|}{ Age (years) } \\
\hline Mean & \multicolumn{2}{|c|}{$36 \cdot 6$} & \multicolumn{2}{|c|}{$36 \cdot 3$} & \multicolumn{2}{|c|}{$37 \cdot 0$} \\
\hline SD & \multicolumn{2}{|c|}{$14 \cdot 2$} & \multicolumn{2}{|c|}{$14 \cdot 3$} & \multicolumn{2}{|c|}{$14 \cdot 1$} \\
\hline \multicolumn{7}{|l|}{ Weight (kg) } \\
\hline Mean & \multicolumn{2}{|c|}{$69 \cdot 7$} & \multicolumn{2}{|c|}{73.4} & \multicolumn{2}{|c|}{$65 \cdot 7^{\star \star *}$} \\
\hline SD & \multicolumn{2}{|c|}{$15 \cdot 5$} & \multicolumn{2}{|c|}{$15 \cdot 1$} & \multicolumn{2}{|c|}{$15 \cdot 0$} \\
\hline \multicolumn{7}{|l|}{ Waist circumference $(\mathrm{cm})$} \\
\hline Mean & \multicolumn{2}{|c|}{$91 \cdot 0$} & \multicolumn{2}{|c|}{$90 \cdot 7$} & \multicolumn{2}{|c|}{91.4} \\
\hline SD & \multicolumn{2}{|c|}{$13 \cdot 5$} & \multicolumn{2}{|c|}{$12 \cdot 8$} & \multicolumn{2}{|c|}{$14 \cdot 3$} \\
\hline \multicolumn{7}{|l|}{ BMI $\left(\mathrm{kg} / \mathrm{m}^{2}\right)$} \\
\hline Mean & \multicolumn{2}{|c|}{$27 \cdot 2$} & & & & \\
\hline SD & & & & & & \\
\hline Fasting glucose $(\mathrm{mmol} / \mathrm{l}) \dagger$ & & & & & & \\
\hline Mean & & & & 56 & & \\
\hline SD & & & & 84 & & 3 \\
\hline Fasting insulin (pmol/l)† & & & & & & \\
\hline Mean & & & & & & \\
\hline SD & & & & & & \\
\hline HOMA-IR $†$ & & & & & & \\
\hline Mean & & & & 77 & & \\
\hline SD & & & & 58 & & 33 \\
\hline Diabetes mellitus $\ddagger$ & 31 & $4 \cdot 1$ & 9 & $2 \cdot 8$ & $22^{*}$ & \\
\hline Hypertension§ & 152 & $19 \cdot 5$ & 74 & $20 \cdot 5$ & 78 & $18 \cdot 4$ \\
\hline Smoker\| & 593 & $78 \cdot 0$ & 253 & $75 \cdot 4$ & $340^{*}$ & $80 \cdot 6$ \\
\hline Alcoholø & & & & & & \\
\hline Non-drinker & 157 & $21 \cdot 2$ & 54 & $16 \cdot 7$ & 103 & $25 \cdot 5$ \\
\hline$\leq 10 \mathrm{~g} / \mathrm{d}$ & 365 & $52 \cdot 7$ & 171 & $56 \cdot 1$ & 194 & $49 \cdot 2$ \\
\hline $10-30 \mathrm{~g} / \mathrm{d}$ & 126 & $18 \cdot 8$ & 66 & $20 \cdot 9$ & 60 & $16 \cdot 6$ \\
\hline$\geq 30 \mathrm{~g} / \mathrm{d}$ & 50 & $7 \cdot 4$ & 18 & $6 \cdot 0$ & $32^{* *}$ & 8.7 \\
\hline Bay of residence (\% Hudson) & 486 & $63 \cdot 1$ & 212 & $62 \cdot 6$ & 274 & 63.5 \\
\hline Educationt† & & & & & & \\
\hline Elementary completed or less & 173 & $22 \cdot 8$ & 69 & $21 \cdot 5$ & 104 & $24 \cdot($ \\
\hline Secondary not completed & 404 & $54 \cdot 5$ & 180 & $54 \cdot 9$ & 224 & $54 \cdot$ \\
\hline Secondary completed or higher & 169 & $22 \cdot 7$ & 79 & $23 \cdot 6$ & 90 & $21 \cdot \varepsilon$ \\
\hline Incomeł‡ & & & & & & \\
\hline$<\$ 20000 /$ year & 357 & 53.9 & 161 & $52 \cdot 3$ & 196 & $55 \cdot \varepsilon$ \\
\hline$\$ 20000$ to $<40000 /$ year & 180 & $26 \cdot 2$ & 80 & $24 \cdot 7$ & 100 & \\
\hline$\geq \$ 40000 /$ year & 137 & $19 \cdot 9$ & 76 & $23 \cdot 0$ & $61^{*}$ & $16 \cdot 3$ \\
\hline
\end{tabular}

HOMA-IR, homeostatic model assessment of insulin resistance ${ }^{(25)}$.

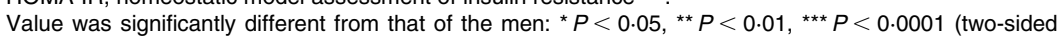
Student's $t$ test for continuous variables and $\chi^{2}$ test for categorical variables).

$\dagger$ Calculations excluded individuals fasting for less than $8 \mathrm{~h}$ ( $n$ 104; forty-eight males and fifty-six females). $\ddagger$ Diabetes mellitus was defined as fasting plasma glucose $\geq 7 \mathrm{mmol} / /^{(51)}$ and/or taking glucose-lowering medication.

$\S$ Hypertension was defined as systolic blood pressure $\geq 140 \mathrm{mmHg}$ and/or diastolic blood pressure $\geq 90 \mathrm{mmHg}^{(52)}$ and/or taking blood pressure-lowering medication.

|| Proportion based on 763 (339 males and 424 females) non-missing observations.

I Proportion based on 696 (309 males and 389 females) non-missing observations.

†† Proportion based on 746 (328 males and 418 females) non-missing observations.

†† Proportion based on 674 (317 males and 357 females) non-missing observations.

did men $(10 \cdot 1$ v. $8.9 \% ; P<0 \cdot 0001)$. In both sexes, DHA contributed the most to the total of $n-3$ fatty acids $(5 \cdot 3 \%)$.

\section{Trans-fatty acid food sources}

The simple Pearson correlation coefficients of erythrocyte TFA with the mean annual consumption of potential food contributors as assessed through FFQ are reported in Table 4. We observed that overall, potential sources of industrially produced TFA (for example, products susceptible of containing partially hydrogenated vegetable oils) such as French fries, pastries, margarine, sweets + chocolate bars + candies, as well as chips (potato crisps) were all significantly and positively correlated with blood TFA. Though usually fried, bannock was negatively associated with TFA, probably due to the popularity of lard to prepare that Inuk bread.

\section{Association between trans-fatty acid and plasma lipid concentrations}

Tables 5 and 6 report the $\beta$ coefficient estimates and $P$ values from multiple regressions performed with TFA and different sets of covariates respectively in Inuit men and women. The associations varied markedly between the sexes. 
Table 2. Baseline plasma lipid profiles of study participants (Mean values and standard deviations or numbers of participants and percentages)

\begin{tabular}{|c|c|c|c|c|c|c|}
\hline & \multicolumn{2}{|c|}{ All $(n 795)$} & \multicolumn{2}{|c|}{ Men $(n$ 357) } & \multicolumn{2}{|c|}{ Women ( $n$ 438) } \\
\hline & Mean & SD & Mean & SD & Mean & SD \\
\hline \multicolumn{7}{|l|}{ Fasting for less than $8 \mathrm{~h}$} \\
\hline$n$ & \multicolumn{2}{|c|}{100} & \multicolumn{2}{|c|}{45} & \multicolumn{2}{|c|}{55} \\
\hline$\%$ & \multicolumn{2}{|c|}{$13 \cdot 5$} & \multicolumn{2}{|c|}{$14 \cdot 0$} & \multicolumn{2}{|c|}{$13 \cdot 1$} \\
\hline \multicolumn{7}{|l|}{ Fasting $T A G \geq 1.7 \mathrm{mmol} / \mathrm{l}$} \\
\hline$n$ & \multirow{2}{*}{\multicolumn{2}{|c|}{$\begin{array}{c}97 \\
11.3\end{array}$}} & \multirow{2}{*}{\multicolumn{2}{|c|}{$\begin{array}{c}42 \\
10.9\end{array}$}} & \multirow{2}{*}{\multicolumn{2}{|c|}{55}} \\
\hline$\%$ & & & & & & \\
\hline \multicolumn{7}{|l|}{ Lipid-lowering medication† } \\
\hline$n$ & \multirow{2}{*}{\multicolumn{2}{|c|}{$\begin{array}{c}47 \\
5.5\end{array}$}} & \multirow{2}{*}{\multicolumn{2}{|c|}{$\begin{array}{l}20 \\
5.0\end{array}$}} & \multicolumn{2}{|c|}{27} \\
\hline$\%$ & & & & & $6 \cdot 0$ & \\
\hline $\mathrm{TC}(\mathrm{mmol} / \mathrm{l})$ & 4.94 & 1.01 & 4.86 & 1.03 & $5 \cdot 04^{\star \star}$ & 0.99 \\
\hline HDL-C (mmol/l) & 1.65 & 0.49 & 1.49 & 0.41 & $1.82^{\star \star \star}$ & 0.50 \\
\hline LDL-C (mmol/l) & $2 \cdot 78$ & 0.88 & $2 \cdot 83$ & 0.91 & $2 \cdot 72^{\star}$ & 0.83 \\
\hline Non-HDL-C (mmol/l) & 3.29 & 1.00 & $3 \cdot 36$ & 1.05 & $3 \cdot 22^{*}$ & 0.94 \\
\hline TAG $(\mathrm{mmol} / \mathrm{l})$ & 1.13 & 0.61 & $1 \cdot 15$ & 0.62 & $1 \cdot 10$ & 0.59 \\
\hline TC:HDL-C & $3 \cdot 2$ & 1.1 & 3.5 & $1 \cdot 1$ & $2 \cdot 9^{\star \star \star}$ & 0.9 \\
\hline LDL-C:HDL-C & 1.8 & 0.9 & $2 \cdot 1$ & 0.9 & $1 \cdot 6^{\star \star \star}$ & 0.7 \\
\hline TAG:HDL-C & 0.78 & 0.60 & 0.87 & 0.67 & $0.68^{\star \star \star}$ & 0.50 \\
\hline ApoA1 (g/l) & $1 \cdot 70$ & 0.31 & 1.62 & 0.28 & $1 \cdot 78^{\star \star \star}$ & 0.32 \\
\hline ApoB100 (g/l) & 0.94 & 0.24 & 0.95 & 0.25 & 0.93 & 0.23 \\
\hline ApoB100:apoA1 & 0.57 & 0.18 & 0.60 & $0 \cdot 18$ & $0.54^{\star \star \star}$ & $0 \cdot 16$ \\
\hline LDL integrated particle diameter $(\AA)$ & $255 \cdot 8$ & $2 \cdot 0$ & $255 \cdot 3$ & $2 \cdot 0$ & $256 \cdot 2^{\star \star \star}$ & 1.9 \\
\hline LDL peak particle diameter $(\AA)$ & $255 \cdot 7$ & $2 \cdot 7$ & 255.4 & $2 \cdot 8$ & $256 \cdot 1^{\star \star \star}$ & $2 \cdot 5$ \\
\hline
\end{tabular}

TC, total cholesterol; HDL-C, HDL-cholesterol; LDL-C, LDL-cholesterol.

Value was significantly different from that of the men: ${ }^{\star} P<0.05,{ }^{\star \star} P<0.01,{ }^{\star \star \star} P<0.0001$ (two-sided Student's $t$ test for continuous variables and $\chi^{2}$ test for categorical variables).

† Lipid-lowering drug(s) taken at the time of blood sampling according to the review of participants' medical charts.

In men the strongest association, which was also the most stable to different types of adjustments, was found between TFA and the three atherogenic indexes of plasma (LDLC:HDL-C, TC:HDL-C, TAG:HDL-C) and consistently, with
HDL-C. Although the $\beta$ coefficient and $R^{2}$ of models were very small, the association between LDL peak particle diameter and TFA was negative and statistically significant in all three models tested. The association between TFA and the

Table 3. Baseline fatty acid content in erythrocytes of study participants $†$ (Mean values and standard deviations)

\begin{tabular}{|c|c|c|c|c|c|c|}
\hline & \multicolumn{2}{|c|}{ All $(n 795)$} & \multicolumn{2}{|c|}{ Men $(n 357)$} & \multicolumn{2}{|c|}{ Women ( $n$ 438) } \\
\hline & Mean & SD & Mean & SD & Mean & SD \\
\hline Total trans-fatty acids $\ddagger$ & $1 \cdot 20$ & 0.54 & $1 \cdot 24$ & 0.54 & $1 \cdot 16^{\star \star}$ & 0.54 \\
\hline Elaidic acid (trans-18:1n-9) & 0.63 & 0.60 & 0.63 & 0.62 & 0.62 & 0.59 \\
\hline Vaccenic acid (trans-18:1n-7) & 0.56 & 0.48 & 0.60 & 0.50 & $0.52^{\star *}$ & 0.46 \\
\hline Trans-18:2 isomers & 0.01 & 0.00 & 0.01 & 0.00 & 0.01 & 0.00 \\
\hline$n-3$ Fatty acids $\S$ & 9.5 & 3.6 & 8.9 & 3.6 & $10 \cdot 1^{\star \star \star}$ & 3.4 \\
\hline EPA & 1.6 & $1 \cdot 3$ & 1.5 & $1 \cdot 3$ & $1 \cdot 8^{\star \star \star}$ & $1 \cdot 3$ \\
\hline DPA & $2 \cdot 1$ & 0.5 & $2 \cdot 1$ & 0.5 & $2 \cdot 2^{\star \star}$ & 0.5 \\
\hline DHA & $5 \cdot 3$ & 1.9 & $5 \cdot 0$ & $2 \cdot 0$ & $5 \cdot 7^{\star \star \star}$ & $1 \cdot 8$ \\
\hline$E P A+D H A$ & $7 \cdot 0$ & $3 \cdot 1$ & 6.4 & $3 \cdot 1$ & $7 \cdot 5^{\star \star \star}$ & 2.9 \\
\hline$n-6$ Fatty acids $\|$ & $26 \cdot 0$ & $4 \cdot 3$ & $26 \cdot 6$ & 4.4 & $25 \cdot 4^{\star \star \star}$ & $4 \cdot 1$ \\
\hline
\end{tabular}

DPA, docosapentaenoic acid.

Mean value was significantly different from that of the men: ${ }^{\star} P<0.05,{ }^{\star \star} P<0.01,{ }^{\star \star \star} P<0.0001$ (two-sided Student's $t$ test).

$\dagger$ Expressed as the mean percentage of total fatty acids in erythrocyte membrane phospholipids.

$\ddagger$ The total of trans-fatty acids was calculated as the sum of: trans-9-14:1+trans-9-16:1+trans6-18: 1 + trans-9-18: 1 + trans-11-18: 1 + trans-9, trans-12-18:2 + trans-9, cis-12-18:2 + cis-9, trans12-18:2 + trans-9, trans-12, trans-15-18:3 + trans-11-20:1.

$\S$ The total of cis- $n-3$ fatty acids was calculated as the sum of: cis-4, cis-7, cis-10, cis-13, cis-16, cis-19-22: 6 (DHA) + cis-5, cis-8, cis-11, cis-14, cis-17-20:5 (EPA) + cis-13, cis-16, cis-19-22:3 + cis-8, cis-11, cis-14, cis-17-20:4 + cis-11, cis-14, cis-17-20:3 (eicosatetraenoic) + cis-6, cis-9, cis-12, cis-15-18:4 + cis-9, cis-12, cis-15-18: 3 ( $\alpha$-linolenic acid) + cis-7, cis-10, cis-13, cis-16, cis-19-22:5 (DPA).

$\|$ The total of cis- $n-6$ fatty acids was calculated as the sum of: cis-9, cis-12-18:2 (linoleic acid) + cis-6, cis-9, cis-12-18:3 + cis-11, cis-14-20:2 + cis-8, cis-11, cis-14-20:3 + cis-5, cis-8, cis-11, cis-14-20:4 (arachidonic acid) + cis-13, cis-16-22:2 + cis-7, cis-10, cis-13, cis-16-22:4 + cis-10, cis-13, cis-16-22:5. 

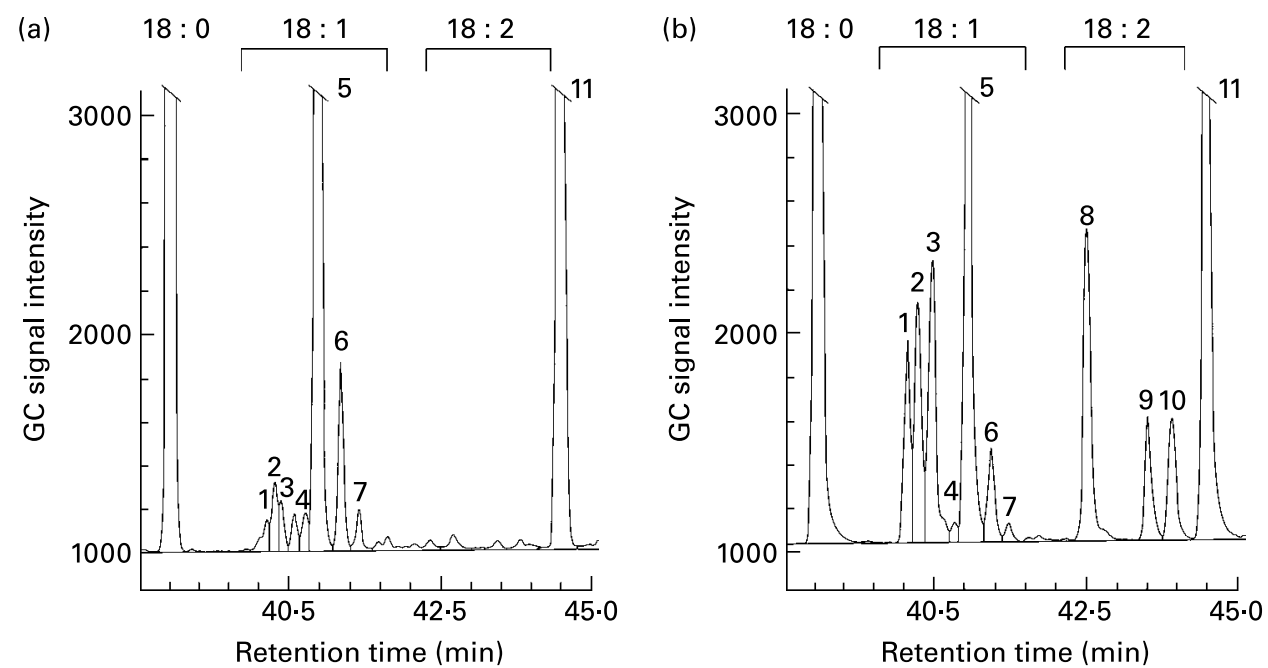

Fig. 1. Gas-liquid chromatogram of erythrocyte membrane fatty acids from a typical subject presenting 18:1 and 18:2 fatty acid profiles (a). All compounds were separated using an HP-88 column designed to fractionate trans-fatty acids according to their retention time. This erythrocyte profile shows the following fatty acids: $18: 0$, trans-6-18:1 (1), trans-9-18: 1 (2), trans-11-18: 1 (3), cis-6-18: 1 (4), cis-9-18:1 (5), cis-11-18:1 (6), cis-12-18:1 (7) and cis-9, cis-12-8:2 (10) 18:2 Trans-fatty acids were not detected. The same fatty acid profile was spiked with a standard mixture of $18: 1$ and $18: 2$ fatty acids (b) composed of trans-6-18:1 (1), trans-9-18:1 (2), trans-11-18:1 (3), trans-9, trans-12-18:2 (8), equal amounts of two $18: 2$ isomers: cis-9, trans-12 and trans-9, cis-12 (9 or 10), and cis-9, cis-12-18:2 (11) $(14,18,23,25,10,10,5 \%$ by weight). Figure (b) shows expected retention times of $18: 2$ trans-fatty acids (peaks 8 to 10) not detected in Fig. (a).

apoB100:apoA1 ratio was positive and significant in model 1 (adjusted for age, waist girth, fasting status, elevated TAG, lipid-lowering medication use and region of residence) and model 2 (further adjusted for $n-3$ and $n-6$ fatty acids) but not in model 3 (which included smoking and alcohol drinking). The association of TFA with LDL-C, non-HDL-C and apoB100 was positive and significant in model 2 only. If instead of adding $n-3$ and $n-6$ fatty acids as covariates we performed regressions including SFA intakes as assessed through FFQ, we still observed a significant negative association of TFA with HDL-C, LDL integrated particle diameter and LDL peak particle diameter and a positive association with LDL-C:HDL-C, TC:HDL-C, TAG:HDL-C and the apoB100:apoA1 ratios but not with other parameters (data not shown). In every model tested, TFA explained only a very small proportion of the variance of the outcome of interest (typically less than $5 \%$ ).

In women, in spite of a larger sample size, no such significant associations were observed, except for HDL-C in model 1 (see Table 6) and after further adjustment for SFA intakes (data not shown), though the negative $\beta$ coefficient was small and the $P$ value was just below $5 \%$. We further performed a separate analysis for likely peri- and post-menopausal women (aged 50 years old or more ( $n$ 94); TFA 0.74 (SD 0.42$) \%$ ) and found a significantly negative association between TFA and HDL-C with models 1 and 2 and close to significance for apoA1 with models 2 and 3 (data not shown). Moreover, although the $P$ values were high, probably

Table 4. Pearson correlation coefficients of trans-fatty acids (TFA) in erythrocyte membrane phospholipids with potential food contributors as assessed through FFQ

\begin{tabular}{|c|c|c|c|c|c|c|}
\hline \multirow[b]{2}{*}{ Food item/group } & \multicolumn{2}{|c|}{ All ( $n$ 624) } & \multicolumn{2}{|c|}{ Men ( $n$ 270) } & \multicolumn{2}{|c|}{ Women (n 354) } \\
\hline & $r$ & $P$ & $r$ & $P$ & $r$ & $P$ \\
\hline \multicolumn{7}{|c|}{ Potential sources of industrially produced TFA } \\
\hline French fries & 0.147 & 0.000 & $0 \cdot 140$ & 0.022 & $0 \cdot 167$ & 0.002 \\
\hline Pastries & 0.113 & 0.005 & 0.134 & 0.028 & 0.078 & $0 \cdot 14$ \\
\hline Margarine & 0.113 & 0.005 & 0.194 & 0.001 & 0.046 & 0.39 \\
\hline Sweets, chocolate bars, candies & 0.088 & 0.028 & 0.089 & 0.15 & 0.083 & 0.12 \\
\hline Chips (potato crisps) & 0.079 & 0.050 & 0.120 & 0.050 & 0.046 & 0.39 \\
\hline Fried chicken & 0.024 & 0.58 & 0.001 & 0.99 & 0.045 & 0.40 \\
\hline Bannock & -0.109 & 0.007 & -0.101 & $0 \cdot 10$ & -0.183 & 0.000 \\
\hline Total breakfast cereals & -0.102 & 0.011 & -0.170 & 0.005 & -0.012 & 0.82 \\
\hline \multicolumn{7}{|c|}{ Potential sources of natural (animal) TFA } \\
\hline All dairy products & -0.054 & $0 \cdot 18$ & -0.037 & 0.54 & -0.092 & 0.09 \\
\hline Country meats & -0.033 & 0.41 & -0.037 & 0.55 & -0.040 & 0.46 \\
\hline Pork meat & 0.031 & 0.44 & 0.003 & 0.96 & 0.059 & 0.27 \\
\hline Canned beef & 0.087 & 0.030 & 0.098 & 0.11 & 0.059 & 0.27 \\
\hline Other beef meat & 0.049 & $0 \cdot 27$ & 0.003 & 0.96 & 0.094 & 0.08 \\
\hline Total market meats & 0.063 & 0.12 & 0.027 & 0.66 & 0.083 & 0.11 \\
\hline
\end{tabular}

GC signal intensity 
Table 5. Multiple linear regression analysis of plasma lipids as dependent variables and relative concentration of trans-fatty acids in erythrocyte membrane phospholipids as the main predictor in Inuit ment

(Regression coefficients and standard errors of the estimate)

\begin{tabular}{|c|c|c|c|c|c|c|}
\hline & \multicolumn{2}{|c|}{ Model 1 ( $n$ 357) } & \multicolumn{2}{|c|}{ Model 2 ( $n$ 357) } & \multicolumn{2}{|c|}{ Model 3 ( $n$ 295) } \\
\hline & $\beta$ & SE & $\beta$ & SE & $\beta$ & SE \\
\hline TC & 0.013 & 0.043 & 0.050 & 0.045 & -0.000 & 0.060 \\
\hline HDL-C & $-0.220^{\star \star \star}$ & 0.052 & $-0.177^{\star \star}$ & 0.052 & $-0.195^{\star \star \star}$ & 0.057 \\
\hline LDL-C & 0.119 & 0.073 & $0.156^{\star}$ & 0.075 & 0.090 & 0.097 \\
\hline Non-HDL-C & 0.119 & 0.068 & $0 \cdot 150^{*}$ & 0.069 & 0.0861 & 0.088 \\
\hline TAG $\ddagger$ & 0.119 & 0.103 & 0.104 & 0.108 & 0.111 & 0.124 \\
\hline LDL-C:HDL-C & $0.339^{\star *}$ & 0.100 & $0.333^{\star \star}$ & 0.100 & $0.228^{\star}$ & 0.112 \\
\hline TC:HDL-C & $0.233^{* * *}$ & 0.064 & $0.227^{\star * *}$ & 0.065 & $0.195^{\star *}$ & 0.075 \\
\hline TAG:HDL-C $\ddagger$ & $0.375^{\star \star}$ & 0.112 & $0.313^{\star \star}$ & 0.116 & 0.305 & 0.164 \\
\hline ApoA1 & $-0.081^{\star \star \star}$ & 0.019 & -0.062 & 0.034 & -0.071 & 0.042 \\
\hline ApoB100 & 0.102 & 0.058 & $0.122^{*}$ & 0.059 & 0.048 & 0.080 \\
\hline ApoB100:apoA1 & $0.183^{\star \star}$ & 0.065 & $0.184^{\star \star}$ & 0.065 & 0.119 & 0.081 \\
\hline LDL integrated particle diameter & $-0.005^{\star \star}$ & 0.002 & -0.003 & 0.002 & $-0.004^{\star}$ & 0.002 \\
\hline LDL peak particle diameter & $-0.007^{\star}$ & 0.003 & $-0.007^{\star}$ & 0.003 & $-0.010^{\star *}$ & 0.003 \\
\hline
\end{tabular}

TC, total cholesterol; HDL-C, HDL-cholesterol; LDL-C, LDL-cholesterol.

${ }^{\star} P<0.05,{ }^{\star \star} P<0.01,{ }^{\star * \star} P<0.0001$ ( $P$ value estimates of the test for $\mathrm{H}_{0}$ hypothesis: $\beta=0$ v. $\left.\mathrm{H}_{1}, \beta \neq 0\right)$.

† As both dependent and independent variables were log-transformed to achieve constant error variance, non-correlation and normality of model residuals, regression coefficients should be interpreted in terms of percentage change: a $1 \%$ change in the independent variable explains $\beta \%$ change in the dependent variable. Covariates in model 1 were age, waist girth, fasting status, elevated TAG, lipid-lowering medication use and region of residence. Model 2 further included the proportion of $n-3$ and $n-6$ fatty acids in erythrocyte membrane phospholipids. Model 3 further added smoking (two classes) and alcohol drinking (four classes). All variables were log-transformed except for age.

$\ddagger$ Elevated TAG was not considered as a covariate in these models.

due to lack of power and lower exposure, a number of $\beta$ coefficients increased and showed a sign consistent with what was found in men, in particular as far as TC:HDL-C, LDLC:HDL-C, TAG:HDL-C and apoB100:apoA1 ratios are concerned. On the contrary, we still found no significant association in women aged less than 50 years $(n$ 344) in spite of higher exposures (TFA 1.27 (SD 0.51) \%).
Given that plasma lipid variables are highly correlated, we finally performed principal component analysis on the correlation matrix of TC, TAG, HDL-C, LDL-C, non-HDL-C, apoA1, apoB100, LDL integrated particle diameter and LDL peak particle diameter. This is a data reduction technique that produces successive linear combinations of the variables each accounting for as much of the remaining variance as

Table 6. Regression coefficients from multiple linear regression analysis of plasma lipids as dependent variables and relative concentration of trans-fatty acids in erythrocyte membrane phospholipids as the main predictor in Inuit women†

(Regression coefficients and standard errors of the estimate)

\begin{tabular}{|c|c|c|c|c|c|c|}
\hline & \multicolumn{2}{|c|}{ Model 1 ( $n$ 438) } & \multicolumn{2}{|c|}{ Model 2 ( $n$ 438) } & \multicolumn{2}{|c|}{ Model 3 ( $n$ 368) } \\
\hline & $\beta$ & SE & $\beta$ & SE & $\beta$ & SE \\
\hline TC & -0.062 & 0.036 & -0.030 & 0.034 & 0.009 & 0.041 \\
\hline HDL-C & $-0.096^{*}$ & 0.047 & -0.068 & 0.047 & 0.016 & 0.052 \\
\hline LDL-C & -0.050 & 0.062 & 0.002 & 0.061 & -0.000 & 0.067 \\
\hline Non-HDL-C & -0.048 & 0.051 & -0.012 & 0.051 & -0.001 & 0.058 \\
\hline TAG $\ddagger$ & -0.065 & 0.086 & -0.108 & 0.088 & -0.082 & 0.097 \\
\hline LDL-C:HDL-C & 0.045 & 0.078 & 0.070 & 0.080 & -0.017 & 0.089 \\
\hline TC:HDL-C & 0.034 & 0.045 & 0.038 & 0.047 & -0.008 & 0.054 \\
\hline TAG:HDL-C $\ddagger$ & 0.104 & 0.089 & 0.026 & 0.090 & -0.118 & 0.128 \\
\hline ApoA1 & -0.029 & 0.031 & -0.023 & 0.032 & 0.028 & 0.037 \\
\hline ApoB100 & -0.046 & 0.044 & -0.012 & 0.044 & -0.016 & 0.052 \\
\hline ApoB100:apoA1 & -0.017 & 0.051 & 0.012 & 0.053 & -0.045 & 0.064 \\
\hline LDL integrated particle diameter & 0.000 & 0.002 & 0.001 & 0.002 & -0.001 & 0.002 \\
\hline LDL peak particle diameter & -0.003 & 0.002 & -0.001 & 0.002 & 0.000 & 0.002 \\
\hline
\end{tabular}

TC, total cholesterol; HDL-C, HDL-cholesterol; LDL-C, LDL-cholesterol.

${ }^{*} P<0.05$ ( $P$ value estimate of the test for $\mathrm{H}_{0}$ hypothesis: $\beta=0$ v. $\mathrm{H}_{1}, \beta \neq 0$ ).

$\dagger$ As both dependent and independent variables were log-transformed to achieve constant error variance, non-correlation and normality of model residuals, regression coefficients should be interpreted in terms of percentage change: a $1 \%$ change in the independent variable explains $\beta \%$ change in the dependent variable. Covariates in model 1 were age, waist girth, fasting status, elevated TAG, lipid-lowering medication use and region of residence. Model 2 further included the proportion of $n-3$ and $n-6$ fatty acids in erythrocyte membrane phospholipids. Model 3 further added smoking (two classes) and alcohol drinking (four classes). All variables were log-transformed except for age.

$\ddagger$ Elevated TAG was not considered as a covariate in these models. 
possible. It therefore describes major blood lipid profiles in the data. We found a strong and negative association of TFA with the linear combination of blood lipid parameters indicative of a protective lipid profile in men that remained significant in every model tested. The latter association was only significant in model 1 for women (data not shown).

\section{Discussion}

The proportion of TFA in erythrocyte PL was comparable with that reported by Sun et al. ${ }^{(12)}$ in Northern America as far as trans-monoenes are concerned. People yet did not seem to eat products containing trans-18:2 isomers, which could be related to the types of vegetable oils most widely used in the Canadian food industry. The main potential contributors typically consisted of products of generally low nutritional quality. Although we did not have reliable quantitative information about the TFA content of these foods, a previous market study by Counil et al. (personal communication), based on the extensive list of products sold in Nunavik stores in 2007, revealed that among the foods frequently consumed by Nunavik residents that may contain industrially produced TFA, it was very easy to find TFAfree products in some categories such as breads, cereal bars, chips (potato crisps) and snacks, crackers, oils and fats, and sweetened dried foods; there was on the other hand less choice but still, substitutes were found for peanut butter and spreads, cookies and frozen meals; on the contrary, pastries, salty dried foods (instant meals) and some frozen products (pizzas, French fries and desserts) more scarcely offered TFA-free alternatives. Although this does not give direct information on the relative contribution of single foods to overall intakes, it suggests that the third group of products might persistently and significantly contribute to TFA intakes among Nunavik Inuit for lack of availability of TFA-free alternatives up North.

The associations we found between TFA and blood lipid parameters varied markedly between the sexes and according to age. While TFA was associated with pro-atherogenic lipid profiles in men, especially through a negative association with HDL-C, no such trends were observed in women, except for HDL-C and apoA1 in women aged 50 years and more.

As far as men are concerned, the present results for HDL-C and the TC:HDL-C and LDL-C:HDL-C ratios are very consistent with a recent meta-analysis of twelve randomised controlled trials conducted in Caucasian populations ${ }^{(17)}$, which showed reduced concentrations of HDL-C, a marker of cardiovascular health ${ }^{(29)}$, and increased TC:HDL-C ratio, a powerful predictor of $\mathrm{CHD}^{(30)}$, in the case of isoenergetic replacement of saturated, cis-monounsaturated and cis-PUFA with TFA. Mensink et al. ${ }^{(16)}$ also had reported in a meta-analysis of eight randomised controlled trials that trans-monoenes were the most harmful macronutrient in terms of the TC:HDL$\mathrm{C}$ ratio. Similar associations were reported by Sun et al. ${ }^{(12)}$ both for HDL-C and the LDL-C:HDL-C ratio in the framework of a nested case-control study while Kabagambe et al. ${ }^{(13)}$ reported a negative and significant association between TFA and HDL-C in the baseline of a clinical trial.

Moreover, in accordance with the results reported by Sun et al. ${ }^{(12)}$ for LDL-C, we found a positive association between
TFA and LDL-C, non-HDL-C and apoB100 which became significant after adjustment for $n-3$ fatty acids.

The inverse association found between apoA 1 and TFA is consistent with the observed decrease in HDL-C as TFA increase and have been reported in controlled feeding trials ${ }^{(31-33)}$. ApoA1 could act as an intermediate factor in the relationship between TFA and HDL-C, as suggested by the attenuation of the $\beta$ coefficient when we adjusted regressions for apoA1 in addition to other covariates (data not shown). The same applies to apoB100 and the association between TFA and LDL-C which again was attenuated after further adjustment for apoB100. A kinetic study conducted in postmenopausal hypercholesterolaemic women ${ }^{(34)}$ actually suggests that one of the mechanisms by which TFA alter lipoprotein concentrations relative to other fats is through an increase in HDL-apoA1 and decrease in LDL-apoB100 catabolism.

LDL particle size was negatively associated with TFA, which is consistent with previous results from dietary intervention $^{(35)}$ and experimental ${ }^{(36)}$ studies, yet population studies are scarce. Some data ${ }^{(37-39)}$ but not all ${ }^{(40)}$ suggest that smaller LDL particles confer an independent risk of developing CHD, involving that at a given level of LDL-C, individuals with small LDL particles have greater atherosclerotic risk than those with large-size LDL.

Although the coefficients were persistently positive for TAG, none were significantly different from zero, even after adjustment for $n-3$ fatty acids which again could have obscured the association ${ }^{(41)}$. Inconsistent results have been reported so far on the potential of trans-18:1 isomers to raise serum TAG, which could be due to methodological difficulties in interpreting TAG concentrations because of high biological intra- and inter-individual variability and strong interactions with other lipid factors ${ }^{(42)}$ or to the fact that TFA have very small effects on that blood parameter.

Finally, the robust negative association found with the linear combination of protective factors (high HDL-C, including apoA1, and large LDL particles) underscores the possible implication of TFA in the co-occurrence of single plasma lipid anomalies that sum-up to build potentially pro-atherogenic lipid profiles in a dose-dependent manner.

Although only few observational data are available in premenopausal women, the lack of association we found in this Inuit group, in spite of exposure to TFA similar to those found in men both in terms of central tendency and range, somehow contradicts previous findings that the association between TFA and CHD risk is most evident among women younger than age 65 years $^{(3)}$ and needs further investigation. Most of the few randomised clinical trials conducted both in men and women usually reported pooled results which did not allow the checking for sex differences in physiological response to TFA intake. Moreover, the mean age of female participants varied greatly between studies. In an attempt to answer the criticism that only male subjects were used in most studies related to CHD risk, Judd et al. ${ }^{(43)}$ performed a stratified analysis and reported that the relationship of diet to plasma lipids was very similar for men and women (mean age 42.6 years). More recently, though, the Trans Fatty Acids Collaboration (TRANSFACT) study conducted in forty men and women (mean age 27.6 years) reported significant interaction terms between treatment with industrially 
produced $v$. natural sources of TFA and sex ${ }^{(44)}$. This suggests that the regulation of lipid metabolism by TFA may be partly mediated by sex hormones, at least in younger subjects ${ }^{(45)}$. More generally, the influence of oestrogens on plasma lipid response to different types of dietary fats could be responsible for the lack of association we found between TFA and proatherogenic lipid profiles in this group. Indeed, the Inuit women who participated in the study were predominantly premenopausal (79\% were less than 50 years) and used relatively few oral contraceptives ( $27 \%$ of women less than 50 years). The present results in women aged 50 years and more, although they lack power due to small sample size and lower levels of exposure to TFA, suggest that the potential protective effect exerted by endogenous oestrogens before menopause shifts to a less favourable hormonal milieu in women after menopause ${ }^{(46)}$ which may affect the plasma lipid response to TFA and other dietary factors. Further experimental studies addressing the differential response to dietary fats in male, and in premenopausal and postmenopausal female subjects would help clarify this still largely unexplored area of investigation ${ }^{(47)}$.

Another hypothesis lies in the very high prevalence of central obesity in our female participants $(71 \%$ had a waist circumference $\geq 80 \mathrm{~cm}$ ), as suggested by the 20 years of follow-up of the Nurses' Health Study in which the association between TFA and CHD risk was most evident among women with a BMI lower than $25 \mathrm{~kg} / \mathrm{m}^{2(3)}$. The authors proposed that an attenuated relationship between blood lipids and CHD in women with more insulin resistance might partly explain these observations. Yet, neither the adjustment of regressions on waist circumference and HOMA-IR nor the stratification of analysis by abnormal waist status changed our observations except for LDL size in model 1, which could simply be due to chance (data not shown).

One limitation of the present study is that there are many other extrinsic and intrinsic factors that are known to affect lipid concentrations such as hormonal variation, acute illness, psychological distress, physical activity and diet ${ }^{(48)}$. In particular, residual confounding by unmeasured dietary factors may have occurred and obscured or counteracted some of the expected associations, notably in women. No data assessing individual usual nutrient intakes were available in the present study. Nevertheless, the single $24 \mathrm{~h}$ recall informed by 605 of our participants allowed us to make broad group comparisons that did not show any significant sex difference in the age-adjusted average proportion of energy coming from proteins $(21 \%)$, carbohydrates $(49 \%)$ or total lipids (29\%) - including SFA (9.8\%), PUFA (5\%), and EPA + DHA (less than $1 \%$ ) - the day before the survey.

Another concern stems from the potential clustering of dietary behaviours that may account in part for the observed associations in men and postmenopausal women. Studies conducted in other populations actually reported that individuals with a greater intake of trans-fats may also have a dietary pattern characterised by a greater intake of energy and saturated fats as well as a sedentary lifestyle ${ }^{(49,50)}$. Again, the $24 \mathrm{~h}$ recall allowed us to compare the age-adjusted proportion of energy derived from different classes of macronutrients according to the quartile of exposure to TFA. Although there was no clear linear pattern, the proportion of energy derived from carbohydrates significantly differed between quartiles of
TFA exposure in men (from $46.5 \%$ to $52.3 \% ; P=0.046$ ). Finally, the lack of association reported for the first time among women, and in particular in younger women as opposed to likely postmenopausal women, could be due to some known limitations of observational and cross-sectional design; they would thus need to be reproduced in other populations in order to gain external validity.

The follow-up of the participants of the Inuit Health in Transition Cohort Study will allow us to assess the clinical significance of the associations we observed - which were overall of moderate magnitude - in terms of incidence of cardiovascular events. Additional data relating to specific genetic polymorphism could soon become available, which would help clarify the mechanisms by which blood lipid phenotypes may be (or not) modified by TFA intakes in this population.

\section{Conclusions}

The present results suggest that both sex (that is, male) and age (that is, postmenopausal women) may influence the association between TFA in erythrocytes and deleterious plasma lipid profiles among Canadian Inuit of Nunavik. The cross-sectional associations we found between TFA and pro-atherogenic lipid profiles in Inuit men intimate that even in the presence of high intakes of $n-3$ fatty acids and in young males, TFA could raise the risk of CHD at least through its physiological effects on plasma lipids. Moreover, we reported for the first time a lack of association among Inuit women, and in particular in younger women as opposed to likely postmenopausal women, which could encourage a new avenue of research.

Considering these results and the levels of exposure we reported earlier, the encouraging conclusions of a study we conducted on the feasibility of replacing hydrogenated fats with better-quality fats in the Northern food supply, and the subsequent call for a ban on industrially produced TFA by Inuit leaders in June 2007, the Nunavik Board of Health and Social Services has now decided to work towards the replacement of hydrogenated fats in Northern Québec. This will occur through a strong public-private partnership with food retailers, social marketing of good-quality fats among Nunavik residents, as well as lobbying at the federal and provincial levels so that the Canadian and Québec governments follow the Danish example and take legal action.

\section{Acknowledgements}

The Nunavik Inuit Health Survey from which these data originate was supported by the Ministère de la Santé et des Services Sociaux du Québec, the Nunavik Regional Board of Health and Social Services, the Department of Indian and Northern Affairs of Canada, the Canadian Foundation for Innovation (CFI), the Network of Centres of Excellence of Canada (ArcticNet), the Nasivvik ACADRE Inuit Centre, and the Canadian Institutes of Health Research. M.-L. C.-D. is supported by a post-doctoral fellowship from the Institute of Aboriginal Peoples' Health (CIHR). A. F. is a Canadian Diabetes Association post-doctoral fellow.

The authors declare no conflict of interest. The authors' responsibilities were as follows. E. D. was the principal 
investigator of the study; E. C. proposed the research hypothesis, performed all statistical analyses, interpreted the data and wrote and revised the manuscript; P. J. was responsible for the analysis of fatty acid composition of erythrocyte membranes; B. L. was responsible for the analysis of apo and LDL particle size; M.-L. C.-D. participated in the interpretation of results in light of cardiometabolic profile; A. F. participated in the interpretation of results in light of dietary data. All authors have provided a critical review of the paper.

We wish to thank the Inuit people of Nunavik for their extensive cooperation with this survey. The valuable assistance of Inuit representatives - both members of the survey advisory committee and Inuit leaders from each community - is gratefully acknowledged. We are also grateful to all the professionals, technicians, students, interviewers and clerical staff who worked at each stage of the survey process. Our gratitude is also extended to the staff of the Canadian Coast Guard Ship Amundsen.

\section{References}

1. Ascherio A, Rimm EB, Giovannucci EL, et al. (1996) Dietary fat and risk of coronary heart disease in men: cohort follow up study in the United States. BMJ 313, 84-90.

2. Pietinen P, Ascherio A, Korhonen P, et al. (1997) Intake of fatty acids and risk of coronary heart disease in a cohort of Finnish men. The Alpha-Tocopherol, Beta-Carotene Cancer Prevention Study. Am J Epidemiol 145, 876-887.

3. Oh K, Hu FB, Manson JE, et al. (2005) Dietary fat intake and risk of coronary heart disease in women: 20 years of followup of the Nurses' Health Study. Am J Epidemiol 161, 672-679.

4. Oomen CM, Ocke MC, Feskens EJ, et al. (2001) Association between trans fatty acid intake and 10-year risk of coronary heart disease in the Zutphen Elderly Study: a prospective population-based study. Lancet 357, 746-751.

5. Kuhnlein HV, Receveur O, Soueida R, et al. (2004) Arctic indigenous peoples experience the nutrition transition with changing dietary patterns and obesity. J Nutr 134, 1447-1453.

6. Pars T, Osler M \& Bjerregaard P (2001) Contemporary use of traditional food among Greenlandic Inuit. Arctic 54, 22-31.

7. Blanchet C, Dewailly E, Ayotte P, et al. (2000) Contribution of selected traditional and market foods to the diet of Nunavik Inuit women. Can J Diet Pract Res 61, 50-59.

8. Nobmann ED, Ponce R, Mattil C, et al. (2005) Dietary intakes vary with age among Eskimo adults of Northwest Alaska in the GOCADAN study, 2000-2003. J Nutr 135, 856-862.

9. Searles E (2002) Food and the making of Inuit identity. Food Foodways 10, 55-78.

10. Counil E, Dewailly E, Bjerregaard P, et al. (2008) Trans-polarfat: all Inuit are not equal. Br J Nutr 100, 703-706.

11. Sun Q, Ma J, Campos H, et al. (2007) Comparison between plasma and erythrocyte fatty acid content as biomarkers of fatty acid intake in US women. Am J Clin Nutr 86, 74-81.

12. Sun Q, Ma J, Campos H, et al. (2007) A prospective study of trans fatty acids in erythrocytes and risk of coronary heart disease. Circulation 115, 1858-1865.

13. Kabagambe EK, Tsai MY, Hopkins PN, et al. (2008) Erythrocyte fatty acid composition and the metabolic syndrome: a National Heart, Lung, and Blood Institute GOLDN study. Clin Chem 54, 154-162.

14. Dewailly E, Blanchet C, Lemieux S, et al. (2001) n-3 Fatty acids and cardiovascular disease risk factors among the Inuit of Nunavik. Am J Clin Nutr 74, 464-473.
15. Dewailly E, Blanchet C, Gingras S, et al. (2002) Cardiovascular disease risk factors and $n-3$ fatty acid status in the adult population of James Bay Cree. Am J Clin Nutr 76, 85-92.

16. Mensink RP, Zock PL, Kester ADM, et al. (2003) Effects of dietary fatty acids and carbohydrates on the ratio of serum total to HDL cholesterol and on serum lipids and apolipoproteins: a meta-analysis of 60 controlled trials. Am J Clin Nutr 77, 1146-1155.

17. Mozaffarian D, Katan MB, Ascherio A, et al. (2006) Medical progress - trans fatty acids and cardiovascular disease. $N$ Engl J Med 354, 1601-1613.

18. Institut National de Santé Publique du Québec \& Nunavik Regional Board of Health and Social Services (2007) Nunavik Inuit Health Survey 2004/Qanuippitaa? How are we? Methodological Report. Québec: Institut National de Santé Publique du Québec.

19. Shaikh NA \& Downar E (1981) Time course of changes in porcine myocardial phospholipid levels during ischemia. A reassessment of the lysolipid hypothesis. Circ Res 49, 316-325.

20. Lepage G \& Roy CC (1986) Direct transesterification of all classes of lipids in a one-step reaction. J Lipid Res 27, 114-120.

21. Albers JJ, Warnick GR, Wiebe D, et al. (1978) Multi-laboratory comparison of three heparin- $\mathrm{Mn}^{2+}$ precipitation procedures for estimating cholesterol in high-density lipoprotein. Clin Chem 24, 853-856.

22. Tremblay AJ, Morrissette H, Gagne JM, et al. (2004) Validation of the Friedewald formula for the determination of low-density lipoprotein cholesterol compared with $\beta$-quantification in a large population. Clin Biochem 37, 785-790.

23. Lamarche B, Tchernof A, Mauriege P, et al. (1998) Fasting insulin and apolipoprotein B levels and low-density lipoprotein particle size as risk factors for ischemic heart disease. JAMA 279, 1955-1961.

24. St-Pierre AC, Ruel IL, Cantin B, et al. (2001) Comparison of various electrophoretic characteristics of LDL particles and their relationship to the risk of ischemic heart disease. Circulation 104, 2295-2299.

25. Matthews DR, Hosker JP, Rudenski AS, et al. (1985) Homeostasis model assessment: insulin resistance and $\beta$-cell function from fasting plasma glucose and insulin concentrations in man. Diabetologia 28, 412-419.

26. Pickering TG, Hall JE, Appel LJ, et al. (2005) Recommendations for blood pressure measurement in humans: an AHA scientific statement from the Council on High Blood Pressure Research Professional and Public Education Subcommittee. $J$ Clin Hypertens (Greenwich) 7, 102-109.

27. Lohman T, Roche A \& Martorell R (1988) Skinfold thicknesses and measurement technique. In Anthropometric Standardization Reference Manual, pp. 53-80 [R Lohman, editor]. Champaign, IL: Human Kinetics.

28. Williams CM (2004) Lipid metabolism in women. Proc Nutr Soc 63, 153-160.

29. Genest J (2008) The Yin and Yang of high-density lipoprotein cholesterol. J Am Coll Cardiol 51, 643-644.

30. Stampfer MJ, Sacks FM, Salvini S, et al. (1991) A prospective study of cholesterol, apolipoproteins, and the risk of myocardial infarction. $N$ Engl J Med 325, 373-381.

31. Mensink RP \& Katan MB (1990) Effect of dietary trans fatty acids on high-density and low-density lipoprotein cholesterol levels in healthy subjects. $N$ Engl J Med 323, 439-445.

32. Zock PL \& Katan MB (1992) Hydrogenation alternatives: effects of trans fatty acids and stearic acid versus linoleic acid on serum lipids and lipoproteins in humans. J Lipid Res 33, 399-410.

33. Lichtenstein AH, Ausman LM, Jalbert SM, et al. (1999) Effects of different forms of dietary hydrogenated fats on serum lipoprotein cholesterol levels. N Engl J Med 340, 1933-1940. 
34. Matthan NR, Welty FK, Barrett PH, et al. (2004) Dietary hydrogenated fat increases high-density lipoprotein apoA-I catabolism and decreases low-density lipoprotein apoB-100 catabolism in hypercholesterolemic women. Arterioscler Thromb Vasc Biol 24, 1092-1097.

35. Mauger JF, Lichtenstein AH, Ausman LM, et al. (2003) Effect of different forms of dietary hydrogenated fats on LDL particle size. Am J Clin Nutr 78, 370-375.

36. Mitmesser SH \& Carr TP (2005) Trans fatty acids alter the lipid composition and size of apoB-100-containing lipoproteins secreted by HepG2 cells. J Nutr Biochem 16, 178-183.

37. Berneis KK \& Krauss RM (2002) Metabolic origins and clinical significance of LDL heterogeneity. J Lipid Res 43, 1363-1379.

38. Sacks FM \& Campos H (2003) Clinical review 163. Cardiovascular endocrinology: low-density lipoprotein size and cardiovascular disease: a reappraisal. J Clin Endocrinol Metab 88, $4525-4532$

39. Lamarche B, St-Pierre AC, Ruel IL, et al. (2001) A prospective, population-based study of low density lipoprotein particle size as a risk factor for ischemic heart disease in men. Can J Cardiol 17, 859-865.

40. El HK, van der Steeg WA, Stroes ES, et al. (2007) Value of low-density lipoprotein particle number and size as predictors of coronary artery disease in apparently healthy men and women: the EPIC-Norfolk Prospective Population Study. $J$ Am Coll Cardiol 49, 547-553.

41. Dyerberg J, Eskesen DC, Andersen PW, et al. (2004) Effects of trans- and $n-3$ unsaturated fatty acids on cardiovascular risk markers in healthy males. An 8 weeks dietary intervention study. Eur J Clin Nutr 58, 1062-1070.

42. Roeters van Lennep JE, Westerveld HT, Erkelens DW, et al. (2002) Risk factors for coronary heart disease: implications of gender. Cardiovasc Res 53, 538-549.
43. Judd JT, Clevidence BA, Muesing RA, et al. (1994) Dietary trans fatty acids: effects on plasma lipids and lipoproteins of healthy men and women. Am J Clin Nutr 59, 861-868.

44. Chardigny JM, Destaillats F, Malpuech-Brugere C, et al. (2008) Do trans fatty acids from industrially produced sources and from natural sources have the same effect on cardiovascular disease risk factors in healthy subjects? Results of the Trans Fatty Acids Collaboration (TRANSFACT) study. Am J Clin Nutr 87, 558-566.

45. Knopp RH, Paramsothy P, Retzlaff BM, et al. (2006) Sex differences in lipoprotein metabolism and dietary response: basis in hormonal differences and implications for cardiovascular disease. Curr Cardiol Rep 8, 452-459.

46. Gillmer MD (1992) Mechanism of action/effects of androgens on lipid metabolism. Int J Fertil 37, Suppl. 2, 83-92.

47. Lapointe A, Balk EM \& Lichtenstein AH (2006) Gender differences in plasma lipid response to dietary fat. Nutr Rev 64 , 234-249.

48. Cooper GR, Myers GL, Smith SJ, et al. (1992) Blood lipid measurements. Variations and practical utility. JAMA 267, $1652-1660$.

49. Pereira MA, Kartashov AI, Ebbeling CB, et al. (2005) Fast-food habits, weight gain, and insulin resistance (the CARDIA study): 15-year prospective analysis. Lancet $\mathbf{3 6 5}, 36-42$.

50. Hu FB, Li TY, Colditz GA, et al. (2003) Television watching and other sedentary behaviors in relation to risk of obesity and type 2 diabetes mellitus in women. JAMA 289, 1785-1791.

51. American Diabetes Association (2008) Standards of medical care in diabetes - 2008. Diabetes Care 31, Suppl. 1, S12-S54.

52. Chobanian AV, Bakris GL, Black HR, et al. (2003) Seventh report of the Joint National Committee on Prevention. Detection, Evaluation, and Treatment of High Blood Pressure. Hypertension 42, 1206-1252. 